\title{
Clinical Intelligence
}

Ayodeji O Olubaniyi, Charlotte-Eve Short, Denis Remedios and Moses Kapembwa

\section{An unexpected cause of digital gangrene:}

\author{
HIV associated peripheral arterial thrombosis
}

AO Olubaniyi, MBBS, MSc, DFSRH, clinical fellow; D Remedios, MA, MRCP, FRCR, consultant radiologist; M Kapembwa, PhD, FRCP(Ed), FRCP (Lond), consultant physician and senior lecturer, GUM/HIV, Northwick Park Hospital, Harrow. C-E Short, BMedSc, MRCP. academic clinical fellow, GUM/HIV Medicine, Imperial College Healthcare NHS Trust.

\section{Address for correspondence}

Ayodeji Olubaniyi, Northwick Park Hospital, GUM/HIV, Watford Road, Harrow, HA1 3UJ, UK.

E-mail: ayodeji60dyahoo.com

Submitted: 7 January 2013; final acceptance: 16 January 2012

(c)British Journal of General Practice 2013;

63: 162-163.

DOI: 10.3399/bjgp13X664441

\section{INTRODUCTION}

Patients with human immunodeficiency virus (HIV) have various coagulation abnormalities as well as increased risk for development of clinical thrombosis and subsequent embolic events. We report acute lower-leg ischaemia caused by spontaneous thromboembolism with no identifiable risk other than HIV infection in a black African male. Physicians should be aware that thromboembolic arterial disease without usual risk factors may be secondary to HIV infection. With increased HIV testing in a variety of clinical settings there is likely to be an increase in detection of similar cases.

\section{CASE REPORT}

A 53-year-old West African male was referred to an emergency department (ED) by his GP with a 2-week history of a painful and swollen right foot, unresponsive to oral flucloxacillin. He was a non-smoker. Examination revealed necrosis of the distal right second toe and right hallux with absent right posterior tibial and dorsalis pulses. His temperature was $37.7^{\circ} \mathrm{C}$, blood pressure $121 / 73 \mathrm{mmHg}$ and pulse rate $94 /$ minute, regular. He denied any history of claudication pain, diabetes mellitus, or ingestion of ergotrelated herbal compounds.

Initial investigations showed leucocytosis (white cell count $15.4 \times 10^{9} \mathrm{~L}$, neutrophil $\left.13.4 \times 10^{9} \mathrm{~L}\right)$, with eosinophilia $\left(0.94 \times 10^{9} \mathrm{~L}\right.$ 0.00-0.40), thrombocytopenia (platelets $\left.84 \times 10^{9} \mathrm{~L}\right)$, hypoalbuminaemia (22 g/L), and raised inflammatory markers (C-reactive protein $100 \mathrm{mg} / \mathrm{L}$, erthrocyte sedimentation rate $109 \mathrm{~mm} /$ hour). His HIV antibody was positive; CD4 count 100 cells/ $\mathrm{mm}^{3}$ (11\%), viral load 59974 copies $/ \mathrm{mL}$. Hepatitis C antibody negative. He had elevated anticardiolipin IgG antibodies. Tropical parasite screen (schistosomiasis, strongyloides, and filariasis) was negative. Serum protein electrophoresis showed polyclonal increase in $\lg G$ and $\lg M(\lg G$ $51.7 \mathrm{~g} / \mathrm{L}, \mathrm{lg} M 4.0 \mathrm{~g} / \mathrm{L})$. Negative antinuclear antibodies. Cholesterol $4.2 \mathrm{mmol} / \mathrm{L} / 4.0$ 6.5), triglyceride $2.28 \mathrm{mmol} / \mathrm{L}(0.00-1.70)$. Chest X-ray showed air space shadowing in the right lower zone suggestive of acute infection.

A duplex Doppler ultrasound scan demonstrated patency of the right posterior tibial and peroneal arteries from origin to proximal segment with no flow distally and normal aorta. Abrupt arterial occlusion at the upper peroneal and distal posterior tibial arteries was observed at angiography (Figure 1). Echocardiography and 24-hour ECG monitoring revealed no abnormalities.

He was admitted for management of dry gangrene and treated with intravenous antibiotics (ceftriaxone/flucloxacillin) and started on highly-active antiretroviral therapy (HAART). His temperature settled and he was discharged with plans for elective transmetatarsal forefoot amputation.

When he returned to the HIV clinic 4 weeks later, his second to fifth distal phalanges had undergone autoamputation. The right hallux subsequently required transphalangeal amputation.

Since initial presentation 18 months ago, he has achieved virological suppression (that is, viral load $<50$ RNA copies $/ \mathrm{ml}$ ) on HAART (Atripla ${ }^{\circledR}$, Gilead) with CD4 counts in excess of 600 cells $/ \mathrm{mm}^{3}$.

\section{DISCUSSION}

This case report illustrates limb ischaemia with resultant digital gangrene in a patient with coincidental HIV infection. The remarkable features in the patient's presentation are absence of links with conventional precipitant risk factors for peripheral arterial disease (PAD) such as smoking, diabetes mellitus, cardiovascular disease, or drug use. Interestingly, relatively few reports of peripheral arterial occlusive disease have been described in patients with HIV infection. Consequently, HIV infection was not considered in the differential diagnosis in the emergency department until the patient had been admitted to the 


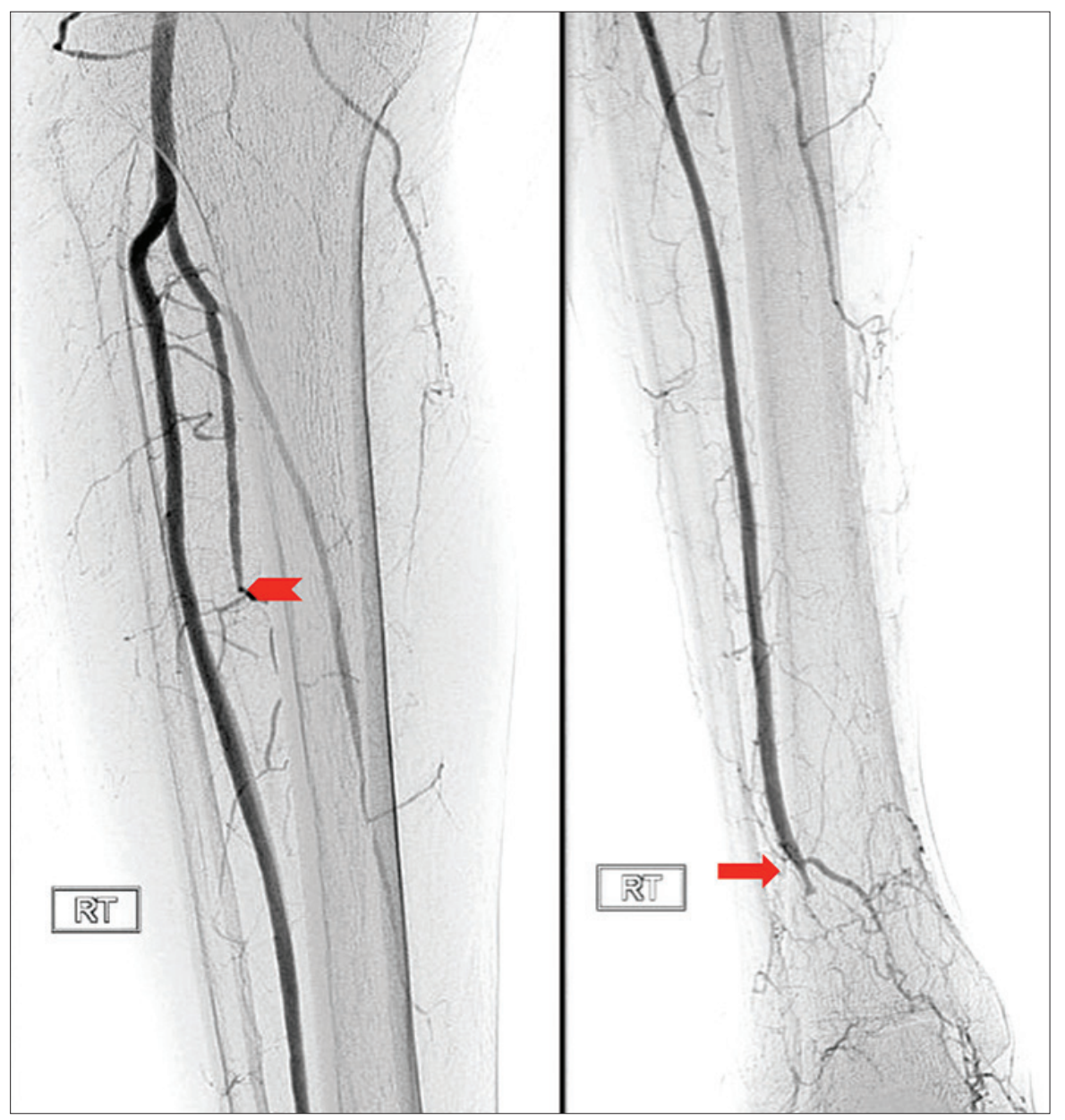

Figure 1. Arteriogram of the right lower leg showing abrupt occlusion at the upper peroneal artery (arrow head [left]) and distal posterior tibial artery (solid arrow [right]).

\section{REFERENCES}

1. Periard D, Cavassini M, Taffé $P$, et al. High prevalence of peripheral arterial disease in HIV-infected persons. Clin Infect Dis 2008; 46(5): 761-767.

2. Mulaudzi TV, Robbs JV, Pillay W, et al. Thrombectomy in HIV related periphera arterial thrombosis: a preliminary report. Eur J Vasc Endovasc Surg 2005; 30(1): 102-106.

3. Strategies for Management of Antiretroviral Therapy (SMART) Study Group; El-Sadr WM, Lundgren J, Neaton JD, et al. CD4+ count-guided interruption of antiretroviral treatment. N Engl J Med 2006; 335(22): 2283-2296.

4. Bagley PH, Scott DA, Smith LS, Schillaci RF. Cytomegalovirus infection, ascending myelitis, and pulmonary embolus. Ann Intern Med 1986; 104(4): 587 ward, a missed opportunity for earlier diagnosis.

PAD is more prevalent in the HIV-infected population than in the general population. A study by Periard et al reported a sixfold increased risk for PAD in HIV-infected individuals as well as earlier onset of the disease compared with HIV-negative patients. ${ }^{1}$ Multivaried analysis in this study identified age, smoking, diabetes, and low CD4 T-cell count $(<200$ cells/ $/ \mu l)$ as significant predictors of PAD. Among most patients critical ischaemia is confined to one limb and, in particular, the lower limbs. ${ }^{2}$ The increased incidence of peripheral arterial disease in HIV infection may be explained, in part, by dyslipidaemia associated with chronic HIV infection and/or antiretroviral treatment (ART) interruptions as shown by the SMART study. ${ }^{3}$ Metabolic side effects of HIV and ART such as lipodystrophy, diabetes mellitus, and insulin resistance may also be associated with premature development of artherosclerosis.

Other abnormalities predisposing to a hypercoagulable state have been detected in HIV patients, including antiphospholipid antibodies, lupus anticoagulant, increased von Willebrand factor, deficiency in protein $\mathrm{C}$ and $\mathrm{S}$, antithrombin, and heparin cofactor. Factors such as opportunistic infections and neoplasm may also contribute to the hypercoagulable state.

The management of HIV-positive patients with arterial occlusion is the same as that for HIV-negative patients. Patients should be offered best medical treatment (smoking cessation, antiplatelet agents, management of hypertension/diabetes) and early vascular referral. HIV-associated vasculopathy and gangrene may be pointers to advanced stages of the disease, as highlighted in our case and warrant early initiation of HAART. In patients wherein the limb cannot be salvaged by thromboembolectomy, thrombolysis, or by-pass procedures, primary amputation should be considered. Patients with recurrent thrombosis should receive long-term prophylaxis with heparin and warfarin.

A well-recognised consequence of HIV infection is immune deficiency resulting from specific depletion of CD4 receptors otherwise known as helper T cells. Such deficiency predisposes individuals to a host of conventional infections, for example, pneumonia as illustrated in the case as well as opportunistic infections. Treatment of intercurrent infection is, therefore, strongly recommended and has been shown to prevent thrombotic events. ${ }^{4}$

In conclusion, this case underscores the importance of early HIV testing and the need for increased testing in emergency departments, vascular clinics, acute admission wards, as well as GP surgeries. Clinicians should always consider HIV infection in their differential diagnosis in patients with gangrene or unresolved cellulitis. Early detection of HIV infection and timely initiation of HAART may prevent vascular complications. Doppler ultrasound is considered the investigation of choice in cases where diagnosis is in doubt.

\section{Patient consent}

The patient has provided written consent for this article to be published.

\section{Provenance}

Freely submitted; not externally peer reviewed.

\section{Discuss this article}

Contribute and read comments about this article on the Discussion Forum: http://www.rcgp.org.uk/bjgp-discuss 